\title{
Serum heat-shock protein-65 antibody levels are elevated but not associated with disease activity in patients with rheumatoid arthritis and ankylosing spondylitis
}

This article was published in the following Dove Press journal:

Open Access Rheumatology: Research and Reviews

Hasan Ulusoy'

Gurkan Akgol ${ }^{2}$

Arif Gulkesen²

Arzu Kaya ${ }^{2}$

Gul Ayden Kal ${ }^{2}$

Dilara Kaman ${ }^{3}$

Turkan Tuncer ${ }^{2}$

'Department of Rheumatology, Medicana International Samsun Hospital, Samsun, Turkey; ${ }^{2}$ Division of Rheumatology, Department of Physical Medicine and Rehabilitation, Firat

University, Faculty of Medicine, Elazig, Turkey; ${ }^{3}$ Department of Biochemistry, Firat University, Faculty of Medicine, Elazig, Turkey
Correspondence: Hasan Ulusoy Department of Rheumatology, Medicana International Samsun Hospital, Yeni Mahalle, Sehit Mesut Birinci Caddesi, No:85, 55080 Samsun, Turkey Mob +90 5340740555

Email ulusoyh@mynet.com
Objectives: Heat-shock proteins (HSPs) have gained increased interest for their role in autoimmune disorders. These proteins are targeted by the immune system in various autoimmune diseases. The aim of this study was to assess the serum heat-shock protein- 65 antibody (antiHSP65) levels and their clinical significance in patients with rheumatoid arthritis (RA) and ankylosing spondylitis (AS).

Patients and methods: A total of 30 patients with RA, 30 patients with AS, and 30 healthy controls were enrolled in this study. All patients were assessed using routine clinical and laboratory evaluations. Serum anti-HSP65 levels were determined by ELISA.

Results: Serum anti-HSP65 levels of both RA and AS patients were significantly higher than those of controls ( $p=0.014$ and $p=0.001$, respectively). No association was found between serum anti-HSP65 levels and disease activity in either RA or AS patients. There was a significant correlation between anti-HSP65 and anti-cyclic citrullinated peptide levels in patients with RA $(p=0.024)$.

Conclusion: In this study, serum anti-HSP65 levels were increased, but not associated with disease activity in both RA and AS patients. These results suggest that HSP antigens may play a role in the pathogenesis. However, further follow-up studies are needed. Identification of target antigens such as HSP65 is vital to developing new immunotherapeutic agents.

Keywords: heat-shock protein, HSP, rheumatoid arthritis, ankylosing spondylitis

\section{Introduction}

Rheumatoid arthritis (RA) and ankylosing spondylitis (AS) are the most common autoimmune inflammatory diseases. ${ }^{1}$ These diseases cause structural damage in the musculoskeletal system, which results in severe pain and functional loss. The genetic, environmental, and immunological causes of these diseases have not been fully defined. However, during the last 2 decades, increased efforts to understand the importance of proinflammatory cytokines have paved the way for new treatment methods. Today, many biological agents that target proinflammatory cytokines are being successfully used in the treatment of RA and AS. ${ }^{2,3}$ On the other hand, anti-cytokine biologics used in the treatment of RA and AS are highly expensive. ${ }^{4}$

In autoimmune diseases, determination of target antigens is of vital importance in understanding the pathogenesis and in developing new treatment strategies. Heatshock proteins (HSPs) are stress proteins that are conserved from microorganisms to 
mammals. HSPs have important functions in cellular integrity during normal and stressful conditions. ${ }^{5,6}$ These proteins have been categorized into different families according to their molecular mass, for example, HSP110, HSP90, HSP70, HSP60, HSP40, HSP20-30, and HSP10 (small HSPs). ${ }^{7,8}$ HSP60 is a mitochondrial chaperonin that is involved in protein folding. For simplicity, HSP60 proteins of diverse origin are referred as HSP65. ${ }^{7}$

Over the years, HSPs have gained increased interests for their role in autoimmune diseases. Data that support the hypothesis that these proteins are targeted by the immune system in RA and AS are increasing. ${ }^{8-11}$ The desensitization with synthetic peptides from HSP65 was shown to suppress inflammation in experimental arthritis models. ${ }^{9,12}$ The use of HSPs and their synthetic peptides for immunotherapy has become an emerging area for the treatment of autoimmune diseases. Previous studies have reported higher serum heatshock protein-65 antibody (anti-HSP65) titers in patients with RA and AS compared to controls..$^{11,13-19}$ However, other studies have shown opposing views on the matter. ${ }^{16,20,21}$ In addition, the relationship between antibodies against HSP65 and disease severity and prognosis has not been sufficiently studied. ${ }^{11,13}$ For this reason, we put together a study to determine the level of serum antibodies against HSP65 and their association with clinical and laboratory parameters in patients with RA and AS.

\section{Patients and methods}

A total of 90 volunteers (RA: 23 females and seven males, mean age, $53.5 \pm 13.2$ years; AS: 13 females and 17 males; mean age, $40.0 \pm 10.9$ years; and healthy controls: 22 females and eight males; mean age, $47.6 \pm 15.6$ years) were recruited for the present study. Patients with RA were selected using the American College of Rheumatology criteria. ${ }^{22}$ Patients with AS were selected with respect to the Modified New York criteria. ${ }^{23}$ Healthy volunteers were chosen among hospital staff. Individuals with any known acute or chronic infections, autoimmune diseases other than RA and AS, malignancies, known severe lung, liver, or kidney diseases, or endocrinological diseases were excluded from the study.

Written informed consent was obtained from all participants according to the Declaration of Helsinki. The local ethics committee of Firat University approved this study. All procedures performed in this study were in accordance with the ethical standards of the national research committee and the 1964 Declaration of Helsinki and its later amendments.

\section{Clinical assessments}

All patients underwent clinical evaluation that included the investigation of pain severity, fatigue, the physician's global assessment, and the patient's global assessment using the visual analog scale. Morning stiffness was evaluated in minutes. The functional conditions of the patients were evaluated with the Health Assessment Questionnaire. ${ }^{24}$ Patients with RA were evaluated using Disease Activity Score-28 (DAS28) and divided into two groups based on disease activity: low (DAS-28 $\leq 3.2$ ) and moderate/high (DAS-28 >3.2) ${ }^{25}$ Six patients were in remission (DAS-28<2.6). Patients with AS were assessed using Bath Ankylosing Spondylitis Disease Activity Index (BASDAI) and Bath Ankylosing Spondylitis Functional Index (BASFI) and divided into low (BASDAI $<4)$ and high (BASDAI $\geq 4$ ) disease activity groups. ${ }^{26,27}$

\section{Laboratory assessments}

All patients underwent routine laboratory evaluations comprising erythrocyte sedimentation rates (ESRs), blood biochemistry, whole blood counts, and urine analyses. The levels of C-reactive protein (CRP) and rheumatoid factor were calculated using the nephelometric method. Anticyclic citrullinated peptides (anti-CCPs) were determined by enzyme-linked immunosorbent assay (ELISA). Blood samples of healthy individuals and patients were centrifuged for 15 minutes at 2,000 rpm, and the obtained serum was kept at $-80^{\circ} \mathrm{C}$. Antibodies against HSP 65 were analyzed by ELISA (Catalog No: CK-E90966; EastBiopharm, Hangzhou, China). Intra- and inter-assay variability percentages for anti-HSP65 were $<10 \%$ and $<12 \%$, respectively.

\section{Statistical analyses}

All statistical analyses were performed with the SPSS 15.0 program. Data were assessed with parametric and nonparametric statistical methods. A Kolmogorov-Smirnov test was used to determine normality. For group comparisons, a chi-square test and an independent $t$-test were used for categorical variables and continuous variables, respectively. For comparison of continuous variables, which did not show normal distribution, the Mann-Whitney $U$-test was used. Any correlation analyses were performed using the Spearman's method. A $p$-value of $<0.05$ was considered as statistically significant.

\section{Results}

The clinical and laboratory results of different groups studied are given in Table 1. No statistically significant difference 
Table I Demographic, clinical, and laboratory characteristics of patients with RA and AS, and their comparisons with those of healthy controls

\begin{tabular}{|c|c|c|c|c|c|}
\hline & $\operatorname{RA}(n=30)$ & AS $(n=30)$ & Controls $(n=30)$ & $p^{a}$ & $p^{b}$ \\
\hline Age (years) & $53.5 \pm \mid 3.2(32-9 \mid)$ & $40.0 \pm 10.9(22-68)$ & $47.6 \pm 15.6(15-77)$ & 0.173 & $0.018^{*}$ \\
\hline Female, n (\%) & $23(76.7)$ & $13(43.3)$ & $22(73.3)$ & 0.167 & 0.213 \\
\hline Disease duration (years) & $9.5 \pm 6.2(I-22)$ & $6 . I \pm 4.8(I-2 I)$ & - & - & - \\
\hline Pain (0-100 mm VAS) & $46.6 \pm 24.1(10-90)$ & $42.8 \pm 18.4(20-90)$ & - & - & - \\
\hline Morning stiffness (minutes) & $5 I \pm 40.3(0-120)$ & $62.8 \pm 41.5(0-120)$ & - & - & - \\
\hline CRP (g/dL) & $8.9 \pm 15.1(0-73)$ & $6.2 \pm 11.0(0-55)$ & $2.3 \pm 2.2(0-8)$ & $0.040 *$ & 0.302 \\
\hline $\operatorname{ESR}(\mathrm{mm} / \mathrm{h})$ & $41.2 \pm 27.4(I-97)$ & $21.6 \pm 18.3(3-67)$ & $13.5 \pm 7.9(2-30)$ & $0.000 *$ & 0.195 \\
\hline $\mathrm{RF}(\mathrm{IU} / \mathrm{mL})$ & $87.7 \pm 110.1(6-588)$ & - & $8.4 \pm 64.7(0-36 \mathrm{I})$ & $0.000 *$ & - \\
\hline Anti-CCP $(\mathrm{U} / \mathrm{mL})$ & $266.4 \pm 366.1(3.7-1000)$ & - & $14.5 \pm 9.4(2.5-46.6)$ & $0.000 *$ & - \\
\hline Anti-HSP65 (ng/mL) & $9.7 I \pm 7.23(0.39-33.70)$ & $15.33 \pm 16.56(1.90-63.60)$ & $7.56 \pm 9.19(0.24-32.80)$ & $0.014^{*}$ & $0.00 I^{*}$ \\
\hline HAQ (0-3) & $1.2 \pm 0.7(10.3-2.60)$ & $2.5 \pm 6.1(0.25-2.6)$ & - & - & - \\
\hline DAS-28 (0-9.4) & $4.5 \pm 2.0(1.28-7.94)$ & - & - & - & - \\
\hline BASDAI $(0-10)$ & - & $4.1 \pm 2.0(1.2-10)$ & - & - & - \\
\hline BASFI (0-10) & - & $3.8 \pm 2.1(1-10)$ & - & - & - \\
\hline
\end{tabular}

Notes: Values are presented as mean \pm SD (range). *Statistically significant result $(p<0.05)$. a Comparison between RA and controls. ${ }^{b}$ Comparison between AS and controls. Abbreviations: RA, rheumatoid arthritis; AS, ankylosing spondylitis; CRP, C-reactive protein; ESR, erythrocyte sedimentation rate; RF, rheumatoid factor; anti-CCP, anti-cyclic citrullinated peptide; anti-HSP65, heat-shock protein-65 antibody; HAQ, Health Assessment Questionnaire; DAS-28, Disease Activity Score-28; BASDAI, Bath Ankylosing Spondylitis Disease Activity Index; BASFI, Bath Ankylosing Spondylitis Functional Index.

between patients with RA and healthy controls was found for mean age and gender. The gender distribution was similar for AS and control groups; however, the mean age was significantly lower in the AS group $(p=0.018)$. The duration of disease for RA and AS patients was 9.5 \pm 6.2 years and $6.1 \pm 4.8$ years, respectively. Although mean ESR and CRP values were significantly higher in patients with RA compared to healthy controls, no statistically significant difference was found between the AS group and the controls (Table 1).

In the RA group, eight (26.6\%) patients received methotrexate monotherapy, $12(40 \%)$ patients were on methotrexate plus prednisolone, three $(10 \%)$ patients were on methotrexate plus hydroxychloroquine, and seven (23.3\%) patients received leflunomide plus prednisolone treatments. In the AS group, seven $(23.3 \%)$ patients were on nonsteroidal anti-inflammatory drug (NSAID) monotherapy, nine (30\%) patients used sulfasalazine plus NSAID, and 14 (46.7\%) patients were on anti-TNF- $\alpha$ treatments.

When comparing with healthy controls, the serum antiHSP65 level in patients with RA was higher and statistically significant ( $p=0.014$; Table 1). Interestingly, no difference was observed for serum anti-HSP65 level in the low and moderate/high disease activity RA groups ( $p=0.683$ ).

When comparing to healthy controls, serum anti-HSP65 level in patients with AS was increased and statistically significant ( $p=0.001$; Table 1 ). When the low and high disease activity AS groups were compared, no difference was observed for serum anti-HSP65 level $(p=0.625)$.
Serum anti-HSP65 levels did not show any association between the disease activity parameters for either the RA group or the AS group (Tables 2 and 3). Interestingly, an association with serum anti-HSP65 and anti-CCP levels was observed ( $p=0.024$; Table 2 ).

Finally, the comparison of serum anti-HSP65 level in the RA and AS groups did not show a difference ( $p=0.451$; Table 1).

\section{Discussion}

In this study, antibodies against HSP65 and its association with disease activity were investigated in patients with RA and AS. Serum anti-HSP65 level was significantly higher for both the RA and the AS groups when compared to the control group. However, there was no association between disease activity parameters and serum anti-HSP65 level in either the RA or the AS group.

HSPs have important functions in innate and adaptive immunity. These proteins bind to the toll-like receptors, activating antigen-presenting cells, and $\mathrm{T}$ and $\mathrm{B}$ lymphocytes. In addition to proinflammatory functions, HSPs are known to evoke the immune-regulatory systems as well. HSPs can stimulate various regulatory $\mathrm{T}$ cells that secrete IL10 and transforming growth factor- $\beta .^{28}$ Interestingly, HSPs can also become targets of immune response and are involved in the pathogenesis of autoimmunity. ${ }^{7}$ In addition, HSPs are involved in the pathogenesis of various diseases, such as atherosclerosis, type 1 diabetes, RA, AS, psoriasis, systemic 
Table 2 Spearman's correlation coefficients $(r)$ for serum antiHSP65 levels and various clinical and laboratory parameters in patients with RA

\begin{tabular}{lll}
\hline & \multicolumn{2}{l}{ Anti-HSP65 } \\
\cline { 2 - 3 } & $\boldsymbol{p}$ & $\boldsymbol{r}$ \\
\hline Morning stiffness & 0.295 & 0.198 \\
Pain & 0.720 & 0.068 \\
ESR & 0.814 & 0.045 \\
CRP & 0.719 & 0.069 \\
RF & 0.408 & 0.157 \\
Anti-CCP & $0.024^{*}$ & 0.411 \\
DAS-28 & 0.409 & 0.156 \\
HAQ & 0.086 & 0.319 \\
\hline
\end{tabular}

Note: *Statistically significant result $(p<0.05)$.

Abbreviations: anti-HSP65, heat-shock protein-65 antibody; RA, rheumatoid arthritis; ESR, erythrocyte sedimentation rate; CRP, C-reactive protein; RF, rheumatoid factor; anti-CCP, anti-cyclic citrullinated peptide; DAS-28, Disease Activity Score-28; HAQ, Health Assessment Questionnaire.

Table 3 Spearman's correlation coefficients $(r)$ for serum antiHSP65 levels and various clinical and laboratory parameters in patients with AS

\begin{tabular}{lll}
\hline & \multicolumn{2}{l}{ Anti-HSP65 } \\
\cline { 2 - 3 } & $\boldsymbol{p}$ & $\boldsymbol{r}$ \\
\hline Morning stiffness & 0.546 & 0.115 \\
Pain & 0.830 & 0.041 \\
ESR & 0.847 & 0.037 \\
CRP & 0.119 & 0.291 \\
BASDAI & 0.875 & 0.030 \\
BASFI & 0.700 & 0.073 \\
HAQ & 0.624 & 0.093 \\
\hline
\end{tabular}

Abbreviations: anti-HSP65, heat-shock protein-65 antibody; AS, ankylosing spondylitis; ESR, erythrocyte sedimentation rate; CRP, C-reactive protein; BASDAI, Bath Ankylosing Spondylitis Disease Activity Index; BASFI, Bath Ankylosing Spondylitis Functional Index; HAQ, Health Assessment Questionnaire.

lupus erythematosus, juvenile dermatomyositis, and Behçet's disease. ${ }^{8,10,17}$

Microbial HSPs can elicit inflammatory responses that may cross-react with self-HSPs or other self-antigens. ${ }^{8}$ Most studies on HSPs focus on the HSP60 family. This family has $>70 \%$ homology between human HSP60 and bacterial HSP65. In previous studies, antibodies against HSP65 have been found in the blood of patients with RA and AS. ${ }^{11,13-17}$ It has also been reported that antibodies against HSP65 were found at higher levels in the synovial fluid than in the peripheral blood of patients with RA. ${ }^{18,19}$

Similar to previous studies, we found that serum antiHSP65 level was elevated in patients with RA compared to healthy controls. However, some researchers have reported no difference in serum anti-HSP65 level between patients with RA and controls. ${ }^{16,20,21}$ In our study, there was no association with disease activity parameters and anti-HSP65 levels. In one study, positive proliferative response of mononuclear cells of patients with RA against HSP60 was reported to be not associated with the severity of disease..$^{29}$

Antibodies against HSP65 have been studied in a few studies clinically in patients with RA and AS. In their study, McLean et al compared the serum anti-HSP65 antibody levels of patients with RA and AS to those of controls. The circulating antibodies against HSP65 in 19 of 55 patients with AS (34.5\%) were shown to be elevated, but there was no statistically significant difference between the AS and control groups. ${ }^{16}$ They did not investigate the association between anti-HSP65 level and other clinical or laboratory parameters. In our study, we observed increased circulating anti-HSP65 levels in patients with AS compared to controls with no association with disease activity. Our findings are consistent with the study of Bodnar et al. ${ }^{13}$ They found increased circulating anti-HSP65 levels in patients with AS, which were not associated with any clinical or laboratory parameters, including ESR, CRP, pain severity, BASDAI, or BASFI. In a recent study, elevated levels of antibodies to human HSP60 were found in patients with spondyloarthritis (SpA). The disease severity assessed by Bath Ankylosing Spondylitis Metrology Index was positively associated with antibodies against human HSP60, especially in the HLA-B27-positive patients. However, there was no association between antibodies against human HSP60 and BASDAI, BASFI, or CRP. ${ }^{11}$

The desensitization obtained by the oral or nasal administration of synthetic peptides from HSP65 was shown to suppress inflammation in experimental arthritis models., ${ }^{9,30-32}$ Shi et $\mathrm{al}^{9}$ administered intranasal synthetic peptides from HSP65 to rats in their experimental arthritis models, and they detected a decrease in serum TNF- $\alpha$ levels and enhanced IL-4. Furthermore, these findings correlated with the histology that showed a reduction in cellular infiltration and synovial hyperplasia. ${ }^{9}$ Three possible mechanisms, including clonal deletion, clonal anergy, and active suppression, may be functional in both nasal- and oral-induced tolerance. ${ }^{31,33}$ A recent study showed that the secretion of proinflammatory cytokines from peripheral blood mononuclear cells of patients with RA was significantly inhibited using peptides synthesized from HSP65. ${ }^{12}$ Another study showed that intravenous administration of HSP10 reduced disease activity and suppressed production of TNF- $\alpha$, IL-1, and IL-6 in patients with RA. ${ }^{34}$ Similarly, orally administered fragment of HSP 40 induced production of regulatory T-cells and IL-4 and IL-10 and decreased production of TNF- $\alpha$ in patients with RA. ${ }^{35}$ Today, there is not enough scientific evidence for the use of synthetic peptides from HSP65 in patients with RA or AS. 
However, one report showed the beneficial effect of an HSP65 fragment on preservation of endogenous insulin production in type 1 diabetes. ${ }^{36}$

However, our study had some limitations, such as it was cross-sectional and included only a small number size of patients. Further investigation of larger patient cohorts and long-term follow-up evaluations is needed to better understand the role of HSPs in RA and AS.

\section{Conclusion}

Our data showed that serum anti-HSP65 levels of patients with RA and AS were higher than those of healthy controls. These results indicate that HSP65 may be involved in the pathogenesis of RA and AS. However, the antibody level was not associated with disease activity, so the theory that HSP65 is a specific part of the etiology cannot be supported by the results of this study. The use of HSPs and their synthetic peptides for immunotherapy has become an emerging area for the treatment of autoimmune diseases. Uncovering novel biomarkers of RA and AS diseases is crucial to better understand the etiology of these diseases and to develop new specific immunotherapeutic agents.

\section{Disclosure}

The authors report no conflicts of interest in this work.

\section{References}

1. Lawrence RC, Helmick CG, Arnett FC, et al. Estimates of the prevalence of arthritis and selected musculoskeletal disorders in the United States. Arthritis Rheum. 1998;41(5):778-779.

2. McInnes IB, Schett G. Cytokines in the pathogenesis of rheumatoid arthritis. Nat Rev Immunol. 2007;7:429-442.

3. Végvári A, Szabó Z, Szántó S, Glant TT, Mikecz K, Szekanecz Z. The genetic background of ankylosing spondylitis. Joint Bone Spine. 2009;76:623-628.

4. Page TH, Brown A, Timms EM, Foxwell BM, Ray KP. Inhibitors of p38 suppress cytokine production in rheumatoid arthritis synovial membranes: does variable inhibition of interleukin- 6 production limit effectiveness in vivo? Arthritis Rheum. 2010;62(11):3221-3231.

5. Schultz DR, Arnold PI. Heat shock (stress) proteins and autoimmunity in rheumatoid diseases. Semin Arthritis Rheum. 1993;22:357-374.

6. Tishler M, Shoenfeld Y. Anti-heat-shock protein antibodies in rheumatic and autoimmune diseases. Semin Arthritis Rheum. 1996;26(2):558-563.

7. Rajaiah R, Moudgil KD. Heat-shock proteins can promote as well as regulate autoimmunity. Autoimmun Rev. 2009;8(5):388-399.

8. Moudgil KD, Thompson SJ, Geraci F, et al. Heat shock proteins in autoimmunity. Autoimmune Dis. 2013;2013:621417.

9. Shi XL, Wang LP, Feng X, et al. Inhibition of adjuvant-induced arthritis by nasal administration of novel synthetic peptides from heat shock protein 65. BMC Musculoskelet Disord. 2014;15:253.

10. Huang MN, Yu H, Moudgil KD. The involvement of heat-shock proteins in the pathogenesis of autoimmune arthritis: a critical appraisal. Semin Arthritis Rheum. 2019;40(2):164-175.

11. Hjelholt A, Carlsen T, Deleuran B, et al. Increased levels of IgG antibodies against human HSP60 in patients with spondyloarthritis. PLoS One. 2013;8(2):e56210.
12. Zhou J, Wang LP, Feng X, Fan DD, Zang WJ, Wang B. Synthetic peptides from heat-shock protein 65 inhibit proinflammatory cytokine secretion by peripheral blood mononuclear cells from rheumatoid arthritis patients. Clin Exp Pharmacol Physiol. 2014;41(1):67-72.

13. Bodnar N, Szekanecz Z, Prohaszka Z, et al. Anti-mutated citrullinated vimentin (anti-MCV) and anti-65 kDa heat shock protein (antihsp65): new biomarkers in ankylosing spondylitis. Joint Bone Spine. 2012;79(1):63-66.

14. Tsoulfa G, Rook GA, Bahr GM, et al. Elevated IgG antibody levels to the mycobacterial $65-\mathrm{kDa}$ heat shock protein are characteristic of patients with rheumatoid arthritis. Scand J Immunol. 1989;30(5):519-527.

15. van Halm VP, Slot MC, Nurmohamed MT, et al. Antibodies against human $60 \mathrm{kDa}$ heat shock protein are not associated with cardiovascular disease in patients with rheumatoid arthritis. Ann Rheum Dis. 2006;65(5):590-594.

16. McLean IL, Archer JR, Cawley MI, Pegley FS, Kidd BL, Thompson PW. Specific antibody response to the mycobacterial $65 \mathrm{kDa}$ stress protein in ankylosing spondylitis and rheumatoid arthritis. Br J Rheumatol. 1990;29(6):426-429.

17. Panchapakesan J, Daglis M, Gatenby P. Antibodies to $65 \mathrm{kDa}$ and 70 $\mathrm{kDa}$ heat shock proteins in rheumatoid arthritis and systemic lupus erythematosus. Immunol Cell Biol. 1992;70(pt 5):295-300.

18. Rudolphi U, Rzepka R, Batsford S, et al. The B cell repertoire of patients with rheumatoid arthritis. II. Increased frequencies of $\mathrm{IgG}_{-}$ and IgA_ B cells specific for mycobacterial heat-shock protein 60 or human type II collagen in synovial fluid and tissue. Arthritis Rheum. 1997;40(8):1409-1419.

19. Oda A, Miyata M, Kodama E, et al. Antibodies to $65 \mathrm{Kd}$ heat-shock protein were elevated in rheumatoid arthritis. Clin Rheumatol. 1994;13(2):261-264.

20. Rudolphi U, Hohlbaum A, Lang B, Peter HH, Melchers I. The B cell repertoire of patients with rheumatoid arthritis. Frequencies and specificities of peripheral blood B cells reacting with human $\operatorname{IgG}$, human collagens, a mycobacterial heat shock protein and other antigens. Clin Exp Immunol. 1993;92(3):404-411.

21. Worthington J, Rigby AS, MacGregor AJ, Silman AJ, Carthy D, Ollier WE. Lack of association of increased antibody levels to mycobacterial hsp65 with rheumatoid arthritis: results from a study of disease discordant twin pairs. Ann Rheum Dis. 1993;52(7):542-544.

22. Arnett FC, Edworthy SM, Bloch DA, et al. American Rheumatism Association 1987 revised criteria for the classification of rheumatoid arthritis. Arthritis Rheum. 1988;31:315-324.

23. Van der Linden S, Valkenburg HA, Cats A. Evaluation of diagnostic criteria for ankylosing spondylitis. A proposal for modification of the New York criteria. Arthritis Rheum. 1984;27(4):361-368.

24. Kucukdeveci AA, Sahin H, Ataman S, et al. Issues in cross-cultural validity: example from the adaptation reliability and validity testing of a Turkish version of the Stanford Health Assessment Questionnaire. Arthritis Care Res. 2004;51(1):14-19.

25. Fransen J, Stucki G, van Riel PL. Rheumatoid arthritis measures: disease activity score (DAS), Disease Activity Score-28 (DAS28), Rapid Assessment of Disease Activity in Rheumatology (RADAR), and Rheumatoid Arthritis Disease Activity Index (RADAI). Arthritis Rheum. 2003;49(suppl 9):214-224.

26. Garrett S, Jenkinson T, Kennedy LG, Whitelock H, Gaisford P, Calin A. A new approach to defining disease status in ankylosing spondylitis: the Bath Ankylosing Spondylitis Disease Activity Index. J Rheumatol. 1994;21(12):2286-2291.

27. Jenkinson TR, Mallorie PA, Whitelock HC, Kennedy LG, Garrett SL, Calin A. Defining spinal mobility in ankylosing spondylitis (AS). The Bath AS Metrology Index. J Rheumatol. 1994;21(9):1694-1698.

28. Coelho V, Broere F, Binder RJ, et al. Heat-shock proteins: inflammatory versus regulatory attributes. Cell Stress Chaperones. 2008;13(2):119-125.

29. Venkatesha SH, Rajaiah R, Berman BM, Moudgil KD. Immunomodulation of autoimmune arthritis by herbal CAM. Evid Based Complement Alternat Med. 2011;9:867-897. 
30. Prakken BJ, Roord S, Van Kooten PJ, et al. Inhibition of adjuvantinduced arthritis by interleukin-10 driven regulatory cells induced via nasal administration of a peptide analog of an arthritis-related heat-shock protein $60 \mathrm{~T}$ cell epitope. Arthritis Rheum. 2002;46(7): 1937-1946.

31. Lorenzo N, Barbera A, Dominguez MC, et al. Therapeutic effect of an altered peptide ligand derived from heat shock protein 60 by suppressing of inflammatory cytokines secretion in two animal models of rheumatoid arthritis. Autoimmunity. 2012;45(6):449-459.

32. Rice JW, Veal JM, Fadden RP, et al. Small molecule inhibitors of Hsp90 potently affect inflammatory disease pathways and exhibit activity in models of rheumatoid arthritis. Arthritis Rheum. 2008;58(12):3765-3775.
33. Wauben $\mathrm{MH}$. Immunological mechanisms involved in experimental peptide immunotherapy of T-cell-mediated diseases. Crit Rev Immunol. 2000;20(6):451-469.

34. Vanags D, Williams B, Johnson B, et al. Therapeutic efficacy and safety of chaperonin 10 in patients with rheumatoid arthritis: a double-blind randomised trial. Lancet. 2006;368(9538):855-863.

35. Prakken BJ, Samodal R, Le TD, et al. Epitope-specific immunotherapy induces immune deviation of proinflammatory $\mathrm{T}$ cells in rheumatoid arthritis. Proc Natl Acad Sci U S A. 2004;101(12):4228-4233.

36. Raz I, Elias D, Avron A, et al. Beta-cell function in new onset type 1 diabetes and immunomodulation with a heat-shock protein peptide (DiaPep277): a randomised double-blind, phase II trial. Lancet. 2001;358(9295):1749-1753.
Open Access Rheumatology: Research and Reviews is an international, peerreviewed, open access journal publishing original research, reports, editorials, reviews and commentaries on all aspects of clinical and experimental rheumatology in the clinic and laboratory including the following topics: Pathology, pathophysiology of rheumatological diseases; Investigation, treatment and management of rheumatological diseases; Clinical trials and novel pharmacological approaches for the treatment of rheumatological disorders. The manuscrip management system is completely online and includes a very quick and fair peer-review system, which is all easy to use. Visit http://www.dovepress.com testimonials.php to read real quotes from published authors. 